\title{
Cassini Titan Radar Mapper
}

\author{
CHARLES ELACHI, FELLOW, IEEE, EASTWOOD IM, LADISLAV E. ROTH, \\ AND CHARLES L. WERNER
}

Invited Paper

Cassini Titan Radar Mapper is a multimode radar instrument designed to probe the optically inaccessible surface of Titan Saturn's largest moon. The instrument is to be included in the payload of the Cassini Saturn Mission. The spacecraft is scheduled for launch in 1995 and is expected to arrive at Saturn and be inserted in orbit around Saturn in late 2003. The individual modes of Cassini Radar Mapper will allow surface imaging at few hundred meters resolution, and topographic mapping. The Mapper will be in operation during close flybys of Titan and will map $\sim 30 \%$ of Titan's surface in the course of the nominal mission.

\section{INTRODUCTION}

With the completion of the Voyager planetary tour and the Magellan observations of Venus, the planetary missions of the last thirty years have provided us with detailed images and associated scientific information about the surfaces of all the solid bodies of the solar system, except for two: Titan and Pluto/Charon. Titan, the largest satellite of Saturn, is completely and continuously covered by a cloud/haze layer (Fig. 1) which masks the surface to visible and infrared imaging systems. Pluto/Charon, the farthest planet/satellite system will not be visited by a spacecraft until well into the twenty-first century.

The Cassini spacecraft, which will be launched in 1995 and will begin orbiting Saturn in late 2003, has the objective of exploring and studying the Saturnian system. In order to observe the surface of Titan and understand its properties and the processes that shaped it, a multipurpose radar will be included in the payload. This instrument, the Cassini Titan Radar Mapper, will be able to operate in two modes: imaging and altimetry.

The paper briefly discusses the requirements that lay behind the design, and describes the configuration and capability of this instrument. Section II addresses our present limited knowledge of the Titanian surface and the

Manuscript received October 15, 1990; revised February 14, 1991. The research described in this paper was carried out at the Jet Propulsion Laboratory, California Institute of Technology, under contract with the Laboratory, California Institute of Technology,
National Aeronautics and Space Administration.

The authors are with the Jet Propulsion Laboratory, California Institute of Technology Pasadena, CA 91109

IEEE Log Number 9100750



Fig. 1. Titan, Saturn's largest satellite, in an image taken by Voyager 2 on August 25, 1981, from a range of 4.5 million kilometers. The satellite is thought to be shrouded by photolytically produced aerosols rather than by the convective clouds found in the atmospheres of Jupiter and Saturn. The aerosol envelope makes Titan's surface inaccesible to probing at optical wavelengths. (JPL P-23929)

measurement requirements imposed on the radar instrument. Section III briefly describes the Cassini mission and the projected orbits. These orbits imposed another set of design constraints which led to the multitude of modes and to an unconventional antenna configuration, described in Section IV. Sections V and VI describe the different radar modes.

\section{State OF Knowledge Of Titan's Surface}

Titan, the largest Saturnian satellite, was discovered by C. Huygens in 1655 , side by side with his discovery of Saturn's rings. An observation of limb darkening of Titan's 
disk (Comas de Sola, 1908) hinted at the possibility that the satellite may possess an atmosphere. Detection of nearinfrared methane bands in Titan's spectrum (Kuiper, 1944) confirmed that an atmosphere was actually present. This finding instantly turned Titan into a unique body among the known moons. Although Earth-based telescopic [1], [2] and, most recently, radar [3] observations have made significant contributions, the bulk of our present knowledge about Titan derives from the Voyager 1 (1980) flyby [4], [5]. Titan was found to be a frigid (near-ground temperature of $\sim 94 \mathrm{~K} \mathrm{[6])} \mathrm{object} \mathrm{whose} \mathrm{surface} \mathrm{is} \mathrm{hidden} \mathrm{by} \mathrm{the} \mathrm{thick}$ (near-ground pressure of $\sim 1.5$ bar [6]), optically opaque atmosphere. The major constituents of this atmosphere are believed to be nitrogen, methane, and perhaps argon [5]. With the mean radius of $2575 \mathrm{~km}$ [6], Titan is known to be the second largest moon in the solar system after Jupiter's Ganymede $(R=2631 \mathrm{~km})$, a body larger than the planet Mercury $(R=2439 \mathrm{~km})$.

The enigmatic veiled surface of Titan is the primary target of the Cassini Titan Radar Mapper. Because so little hard information on the physical state of Titan's surface is available, for the present we have to depend on the often speculative interpretations of the extant data. It can be stated with certainty, however, that the evolution of Titan's surface to its current condition has been coupled to the evolution of the atmosphere. The principal atmospheric process affecting the condition of the surface appears to have been the irreversible photolytic destruction of stratospheric methane in the presence of nitrogen [7], with the attendant escape of atomic hydrogen and the cold-trap condensation and precipitation of the heavier photolytic products (ethane, propane, nitriles, acetylenes) [8], [9]. The suspended photolytic products, forming layers of dirty orange-brownish haze in the stratosphere, have become the source of the observed atmospheric opacity. Titan may have very well evolved into the "smoggiest world in the solar system" [10].

Following the most simplistic speculation, the surface of Titan would consist of liquid ocean or lakes of methane, with land surfaces covered by a layer of solid hydrocarbons. The mean density of Titan $\left(1880 \mathrm{kgm}^{-3}\right)$ implies that the silicate/ice ratio is about 52:48 [5]. Due to its endowment of silicates and to its size, Titan has perhaps been able to develop a sufficient amount of radiogenic heat to sustain some form of methane/ammonia/water volcanism which, in addition to the recurrent outgassing of the interior, would also rejuvenate the exterior. Voyager images of the Jovian icy satellites and of the much smaller (and less dense) Saturnian satellites show evidence of rejuvenation events that were possibly endogenic in origin. Titan might not be an exception. Thus it is reasonable to expect the presence of volcanic features on the surface of Titan, that would be appropriate to the character of the presumed Titanian volcanism.

From the point of view of radar imaging, the issues of existence or nonexistence of ocean or dry land on Titan are of paramount importance. The constitution of the hypothetical dry land depends on the assumed solar nebula composition at Titan's location at the time of accretion and on the moon's subsequent development. If Titan had undergone at least a limited differentiation (i.e., a postaccretionary separation of lighter elements that migrated upwards to form a mantle, from the heavier ones that congregated in the core), the dry land would likely be made up of water ice or of water-ammonia ice, with perhaps some rock also present [11]. Solubility of water in cryogenic nonpolar liquids [12], combined with the action of tidal currents (if ocean exists) [8] and of possible methane precipitation in the troposphere [13], allows for the erosion of the water-ice component of the bedrock [11]. It is not clear whether this could have led to the suppression of the topographic relief of the exposed icy landmass and to the dissolution of the impact-produced scarring. It may have equally well resulted in an evolution of spectacular submerged and perhaps also exposed erosional landforms. If Titan's surface methane budget has been constant over geologic time, then the level of the putative ocean must have been steadily falling. This could have led to the development of comparably spectacular shoreline landforms [14].

The present notions about the gross physical conditions of Titanian ocean are equally speculative. Because the solid phases of the constituents of this ocean would be denser than the liquid phases, any ices, if they formed at all, would sink. Assuming further that the sedimented photolytic derivatives might also sink, the ocean would maintain a free, uniformly smooth surface. The resulting roughness contrast relative to the dry land, detectable in radar images, should be an obvious diagnostic criterion for the classification of these two physiographic provinces and for determination of their areal extent. The experience gained from radar imaging of oceans on earth indicates that at angles of incidence larger than $\sim 20^{\circ}$, the Bragg scattering from small, predominantly capillary waves is the source of the observed image brightness [15], [16]. An interesting question is, could wind-generated capillary waves exist on the surface of Titanian ocean, and if they could, what wavelengths should they be expected to possess? In general, waves of wavelengths of up to a certain characteristic wavelength, denoted here as $\lambda_{m}$, can be considered as capillaries [17], [18]. The characteristic wavelength is given by $\lambda_{m}=2 \pi(\gamma / \rho g)^{1 / 2}$, where $\gamma$ is the surface tension of the fluid, $\rho$ is the fluid density, and $g$ is the acceleration of gravity. On earth, with $\gamma=75 \mathrm{mNm}^{-1}$ for water at $273 \mathrm{~K}$, we obtain $\lambda_{m}=0.017 \mathrm{~m}$. On Titan, the values of $\gamma=31$ $\mathrm{mNm}^{-1}$ at $94 \mathrm{~K}$ [19], [20] and $\rho=700 \mathrm{~kg} \mathrm{~m}^{-3}$ [21], both for ethane, and $g=1.44 \mathrm{~m} \mathrm{~s}^{-2}$, yield $\lambda_{m}=0.034 \mathrm{~m}$. Thus the capillary waves on the surface of Titanian ocean, if they were present, might be expected to span about the same spectrum of wavelengths as do capillary waves on the surface of terrestrial ocean. The wavelength of the Cassini Titan Radar Mapper falls within that spectrum.

To generate pure capillary waves, the elementary theory due to $H$. Jeffreys [17] requires wind speeds lesser than the characteristic speed $U_{m}=3\left(\mu g / s \rho^{\prime}\right)^{1 / 3}$, where $\mu$ is the viscosity of the fluid, $g$ is the acceleration of gravity, $s$ is an 


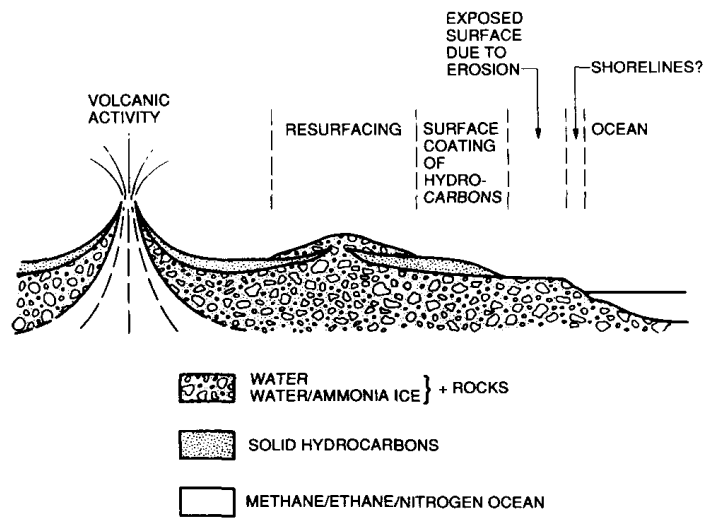

Fig. 2. Schematic cross section of the hypothetical surface of Titan. Only features relevant to the Cassini Titan Radar Mapper are shown.

empirical coefficient, and $\rho^{\prime}$ is the air density. Winds with speeds higher than the characteristic speed $U_{m}$ are expected to excite gravity waves. On earth, with $\mu=0.0018 \mathrm{kgm}^{-1}$ $\mathrm{s}^{-1}$ (viscosity of water at $273 \mathrm{~K}$ ), $s=0.25$, and $\rho^{\prime}=1.25$ $\mathrm{kgm}^{-3}$, we obtain $U_{m}=1.2 \mathrm{~ms}^{-1}$, in rough agreement with observations [17]. For Titan, with the acceleration of gravity about seven times smaller and the air density about five times larger, $U_{m}=0.5 \mathrm{~m} \mathrm{~s}^{-1}$. This is considerably larger than wind speeds predicted by models based on the Voyager IRIS data. Thus observation of gravity waves on Titanian ocean would have significant implications for our notions of the dynamics of the Titanian atmosphere.

One of the key unknowns has been the radar reflectivity of Titan. In 1989, during three successive nights, X-band radar observations of Titan were conducted using the Goldstone radar in California as the transmitter and the Very Large Array (VLA) in New Mexico as the receiver. This experiment provided the first unambiguous radar echo from Titan, which led to the values of normalized mean cross sections of $0.38 \pm 0.15,0.78 \pm 0.15$, and $0.25 \pm 0.15$, for each of the three nights of observations [3]. (For the definition of the terms used in planetary radar astronomy, including that of the normalized cross section, see, e.g., [22], [23].) These cross sections compare with the S-band cross sections of $0.7,0.4$, and 0.2 for the icy Jovian satellites Europa, Ganymede, and Callisto, and are much larger than the cross sections $(0.01$ to 0.08$)$ of all the other known targets in the solar system [24]. The high cross sections of Titan and of Jovian satellites indicate that the surfaces of these moons resemble each other much more than they do the surface of the earth's moon. Assuming synchronous rotation, in three days of the Goldstone/VLA observations the subradar point would have drifted by $\sim 50^{\circ}$ in longitude. The observed variability of Titan's cross section thus also points to a surface of a spatially nonuniform character.

In summary, a hypothetical model of the surface of Titan is shown in Fig. 2. Because of the wide uncertainty in the physical and electrical properties of the surface, we were faced with the situation of designing a radar mapper system which should be flexible enough to adapt to a variety of surface conditions. In light of this, we designed a multimode radar mapper capable of:

- surface imaging at moderate resolution ( $\mathrm{km}$ range), with a wide swath;

- surface imaging at high resolution (400 m range), with a moderate swath;

- topographic mapping by altimetry; and

- scatterometry with very high sensitivity, to study areas of extremely low backscatter.

\section{CASSini Mission Description}

Through its chosen name, the Cassini Mission seeks to pay homage to Giovanni Domenico Cassini, the Director of the Royal Observatory of Paris under Louis XIV, who between 1671 and 1684 discovered Saturn's moons Iapetus, Rhea, Tethys, and Dione (in that order) [25]. In the context of the Copernican disputes that marked the science of Cassini's times these discoveries were of considerable importance because they certified the existence in the solar system of yet another family of secondaries orbiting a primary, in addition to the Jovian family observed by Galileo some seventy years earlier.

The Cassini spacecraft will be launched on a trajectory that includes a gravity assist flyby of Earth and a flyby of Jupiter. It will be inserted in a 32-day orbit around Saturn. During the first four years, the orbiter mission will nominally consist of 59 orbits, with 35 of these allowing a flyby of Titan. A representative Saturn Tour is shown in Fig. 3 , and the corresponding ground tracks on Titan are shown in Fig. 4. Among the planned 35 Titan encounters over the course of the nominal Cassini mission, 29 passes have a minimum altitude at closest Titan approach of less than $4000 \mathrm{~km}$, and 15 of them have a minimum altitude between 950 and $1100 \mathrm{~km}$ at closest approach. The geometry, distribution, and the limited number of Titan flybys impose an important constraint on the radar design, as discussed later. 


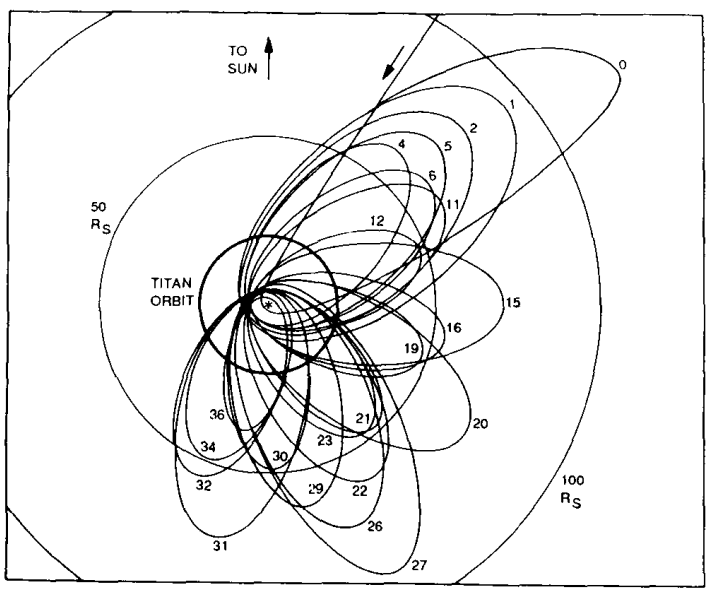

Fig. 3. Representative Saturn Tour (89-01). The symbols $50 R_{S}$ and $100 \mathrm{R}_{\mathrm{S}}$ denote the distances of 50 and 100 Saturn radii, respectively.

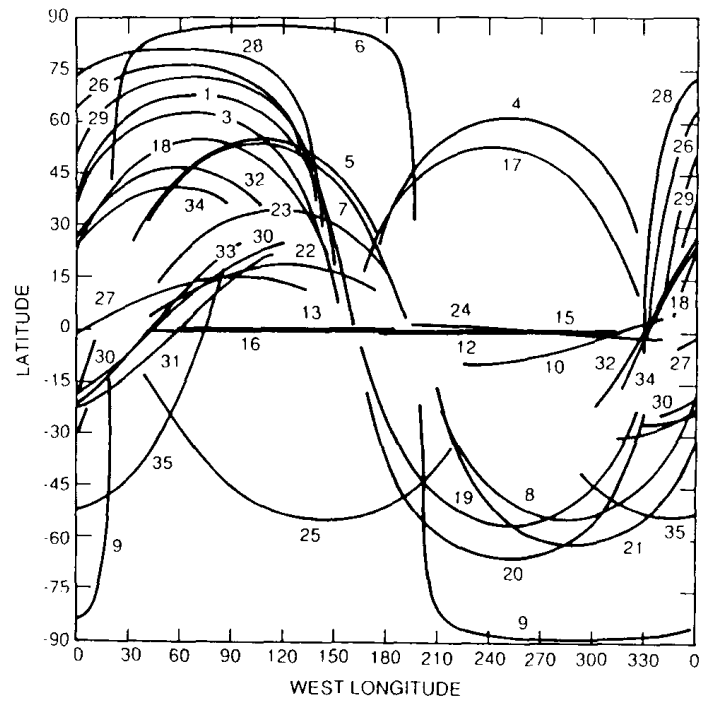

Fig. 4. Ground tracks of Titan flybys for altitudes below 8000 $\mathrm{km}$, during a representative Saturn Tour $(89-01)$.

Another major constraint is the limited weight and volume imposed on the total science payload and therefore on the radar. This led to the decision of using the $3.66-\mathrm{m}$ communication antenna for the radar operations during the flybys. This requires the addition of special antenna feeds to allow radar mapping.

The above science, mission, and spacecraft requirements/constraints led, after a significant amount of analysis and tradeoffs, to the following basic radar configuration.

1) Operating frequency is $13.8 \mathrm{GHz}$, which allows highresolution altimetry with the available antenna, and where flight-qualified power amplifiers are available. At this frequency the effects of Titan's atmosphere are negligible.

2) The imaging should be possible on both sides of the track, to allow maximum coverage during the limited

3) The high-resolution imaging will use the multibeam synthetic aperture radar (SAR) mode during the closest part of the flyby.

4) The medium-resolution imaging will again use the multibeam SAR mode during the inbound and outbound legs.

5) A decision was made to use three beams at each side for radar imaging.

6) Scatterometry and altimetry would possibly be carried out at all times, which implies that the antenna axis will always be nadir pointed. Thus the imaging modes will require special off-axis feeds.

7) In order to further maximize the imaging swath, the imaging beams must be wide (fan-beams) in the cross-track direction.

\section{ANTENNA CONFIGURATION AND INSTRUMENT DESCRIPTION}

As mentioned earlier, the radar utilizes the spacecraft's high-gain, 3.66-m telecommunication antenna reflector. An innovative switched multiple radar feed structure at 13.8 $\mathrm{GHz}$ (Ku-band) will be added to the $\mathrm{X}$ - and Ka-band telecommunication feeds and the S-band radio science feed. A conceptual illustration of the overall feed configuration and the corresponding antenna beam configuration for radar operation are shown in Fig. 5. To meet the rather diverse surface science objectives, a set of antenna requirements has been derived as shown in Table 1 . It can been seen from this table, as well as from Fig. 5, that seven antenna beams, with one pointing at nadir (relative to the center of Titan) and the other six pointing off-nadir, are required for radar operations.

In the current baseline design, a nadir-pointing, circular antenna beam, or the so-called pencil beam, at Ku-band to be used by the altimeter and scatterometer modes will be generated by illuminating the entire dish antenna with a $\mathrm{Ku}$-band feed that is located at the focal point of the main reflector. The off-nadir fan beams are generated by partially illuminating the antenna reflector with a feed array that is offset from the antenna's focal point (see Fig. 6). To create all six beams, it requires two sets of three small linear arrays that are offset located at the opposite side of the reflector axis. The switching between different beams is accomplished by sending computer controlled timing signals to a conventional switching device (electromechanical or diode switch) that is connected to the input ports of the arrays. The principal advantage of this design is that it allows rapid beam switching and accurate beam pointing without physically moving the spacecraft or the reflector dish.

A preliminary design of the Cassini spacecraft's antenna is illustrated in Fig. 7. It is a dual-reflector Cassegrain antenna system. A frequency-selective subreflector (FSS) will 

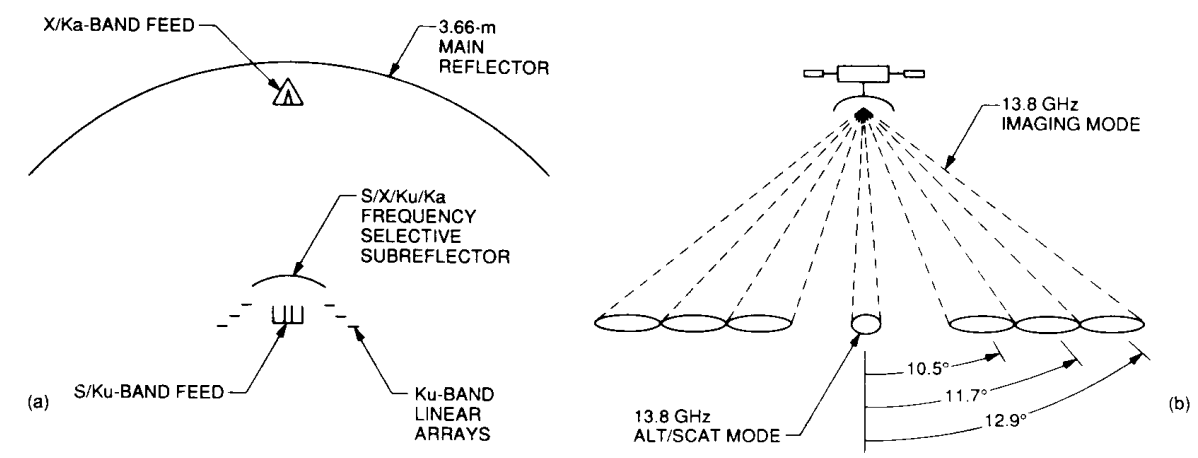

Fig. 5. Conceptual sketches of the Cassini Titan Radar Mapper antenna: (a) The spacecraft reflector antenna system with multiple feeds (X/Ka-band for telecommunications, S-band for radio science, Ku-band for radar); (b) The radar antenna beam pattern.
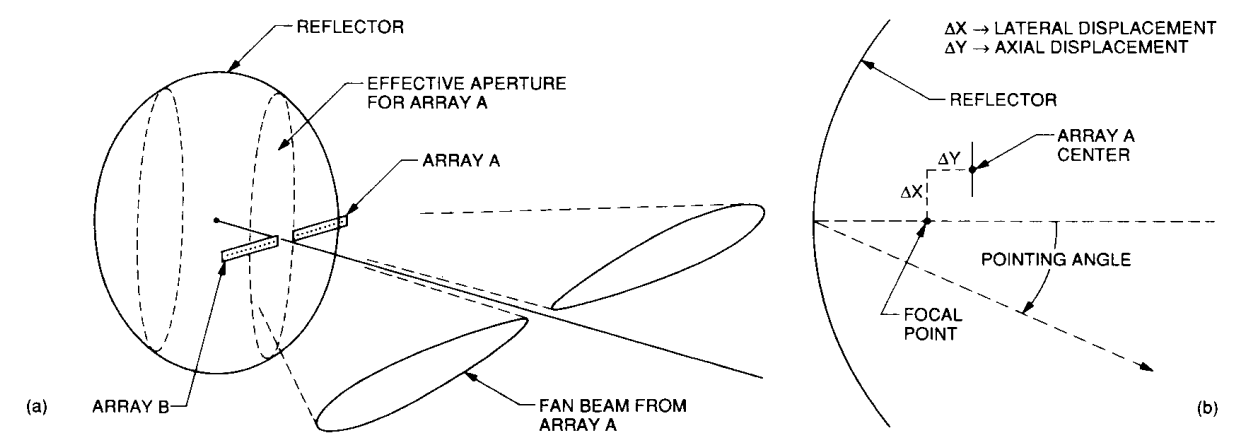

Fig. 6. Conceptual sketches of the Cassini Titan Radar Mapper antenna: (a) Reflector/array configuration for creating off-axis fan beams. (b) Corresponding array displacement from reflector's focal point.

Table 1 Requirements for Titan Radar Mapper`s Antenna

\begin{tabular}{lcc}
\hline \multicolumn{1}{c}{ Parameters } & Imaging & Altimeter/Scatterometer \\
\hline Frequency (GHz) & 13.8 & 13.8 \\
Polarization & HH & HH \\
Peak gain (dB) & 44.0 & 50.4 \\
$\begin{array}{l}\text { Azimuth beamwidth } \\
\text { (deg) }\end{array}$ & 0.45 & 0.4 \\
$\begin{array}{l}\text { Range beamwidth } \\
\text { (deg) }\end{array}$ & 1.2 & 0.4 \\
Look angle (deg) & $\pm 10.5, \pm 11.7, \pm 12.9$ & 0 \\
Peak side-lobe (dB) & -15 & -15 \\
Polarization & linear & linear \\
Peak cross-pol (dB) & -15 & -15 \\
Switch time (ms) & $\leq 25$ & $\leq 25$ \\
$\begin{array}{l}\text { Peak ant. input } \\
\text { power (W) }\end{array}$ & 40 & 40 \\
\hline
\end{tabular}

be designed to reflect the $\mathrm{X} / \mathrm{Ka}$-band telecommunications signals back to the main reflector while being transparent to the S/Ku-band signals. The S-band channel will be used for the radio occultation experiment. Aluminum waveguide at Ku-band will be used to connect the antenna subsystem to the remaining radar electronics located at one of the spacecraft's payload bays. The total insertion losses of the transmission paths between the radar electronics and the antenna ports are estimated to be $2.2 \mathrm{~dB}$ at Ku-band. Calculation shows that the blockage loss at each of the four frequencies due to the presence of the radar feeds is negligible (less than $0.1 \mathrm{~dB}$ of gain reduction).

When a linear array is used to feed a parabolic cylindrical reflector, the reflector surface current in the plane containing the parabolic curvature will have a sine function type response, and the corresponding antenna pattern in the far field will have a fan-beam shape. If the array is displaced along the array axis from the focal point of the reflector having a particular $f / D$ ratio, not only is the beam pointed away from the axis normal to the reflector surface, but the fan beam pattern can also be preserved by properly positioning the array with respect to the reflector's focal plane. Huang and Rahmat-Samii [26] have verified these observations by using both two- and three-dimensional antenna simulation models. An example of the calculated far-field radiation patterns for a two-dimensional reflector with an $f / D$ ratio of 0.33 and for two array locations is 

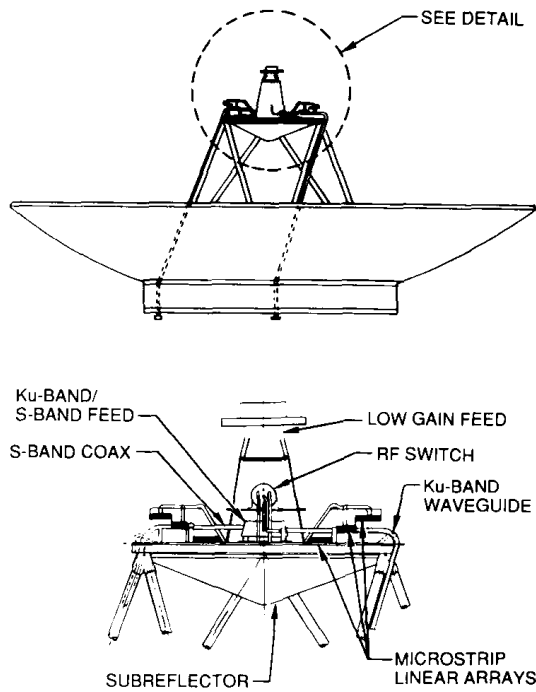

DETAIL

Fig. 7. Preliminary design configuration for the Cassini spacecraft high-gain antenna, incorporating the various feeds on the Cassini spacecraft. (Courtesy of J. Huang.)

shown in Fig. 8. It shows that an angular displacement of $10.5^{\circ}$ can be obtained when the array center is moved 22.9 $\mathrm{cm}$ from the focal point.

To further demonstrate this design concept and to assess its performance in realistic settings, a breadboard model was constructed and test data were collected and analyzed. The breadboard model, as shown in Fig. 8, consists of a 3.66-m parabolic reflector with a $f / D$ ratio of 0.33 , a linear array feed, and a feed support structure which allows the array to move in all three directions. Four-element microstrip arrays were fabricated for this experiment. The element patches were series fed by a microstrip transmission line
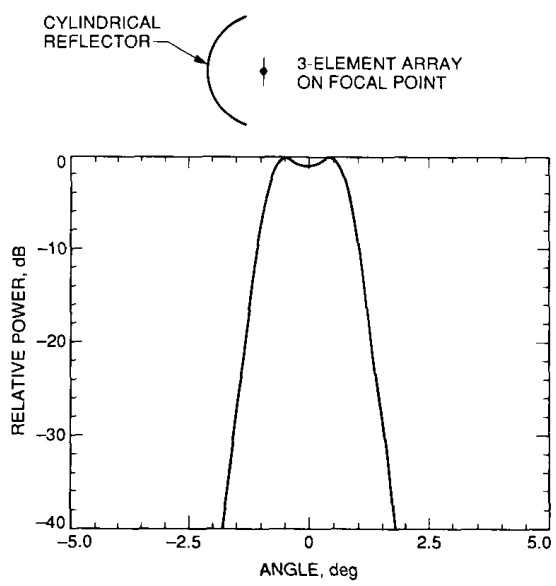

(a) in order to reduce losses. Fig. 9 shows some of the antenna patterns measured during test and Table 2 gives a comparison of the required, calculated, and measured parameters. Except for the antenna sidelobes, the measured parameters match well with the requirements. The antenna sidelobes can be corrected by proper tapering in the final design.

A simplified functional block diagram for the Titan Radar Mapper is shown in Fig. 10. The radar consists of four major subsystems: the antenna subsystem described above, the radio-frequency (RF) subsystem, the digital subsystem, and the power subsystem.

The RF subsystem is responsible for handling all radiofrequency and microwave signals within the instrument. It upconverts and amplifies output signals, and amplifies, downconverts and filters the received echoes. In the present conceptual design a $65-\mathrm{W}$ traveling wave tube amplifier will be used as the output power amplifier. Upon the reception of the controller's commands, the digital chirp (i. e., the linearly frequency-modulated signal) generator of the digital subsystem generates baseband signals of desired modulation and timing characteristics. The phase reference of these signals is provided by a stable frequency source. The output of the chirp generator is upconverted to the desired RF frequency band through a frequency multiplier chain. At this stage, the transmitter amplifies the RF signal to the required peak-transmit-power level. The amplified $\mathrm{RF}$ signal is then routed to the antenna for transmission. Upon reception, radar echoes are amplified by a low-noise amplifier and down-converted to the proper intermediate and baseband frequencies. The baseband signals are then routed to the digital subsystem.

The digital subsystem functions as a central control unit for the radar operations. As such, it accepts and decodes the uplinked commands; maintains a serial communications link to the spacecraft; synchronizes and sequences all radar mode operations with the mission elapsed time clock; controls timing for chirp generation, pulse repetition, burst length, mode multiplexing and range gating; controls the re-
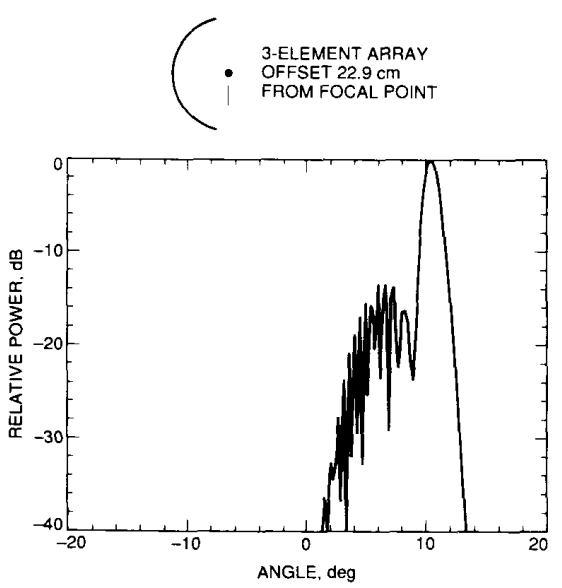

(b)

Fig. 8. Calculated far-field patterns of a parabolic cylindrical reflector fed by a 3-element linear array. Reflector size: $3.65 \mathrm{~m}, f / D=0.333$, frequency $=13.8 \mathrm{GHz}$. (Courtesy of J. Huang.) 


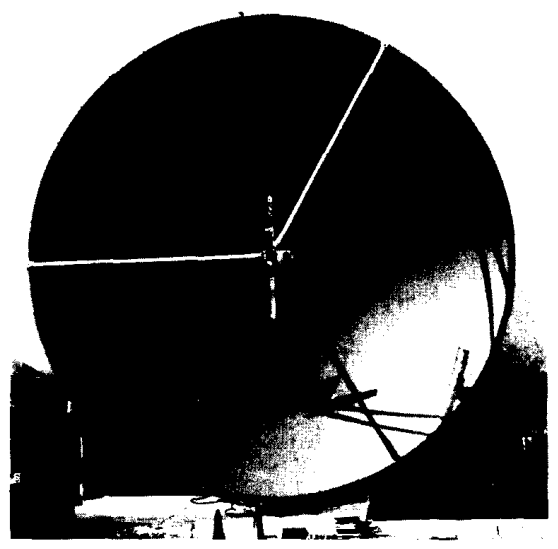

(a)

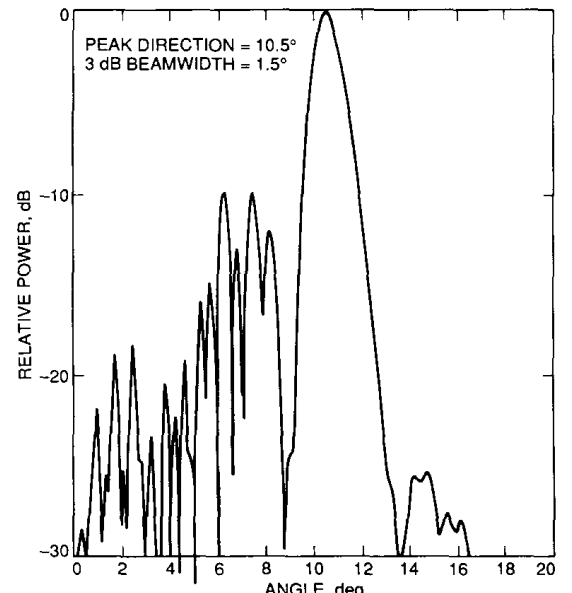

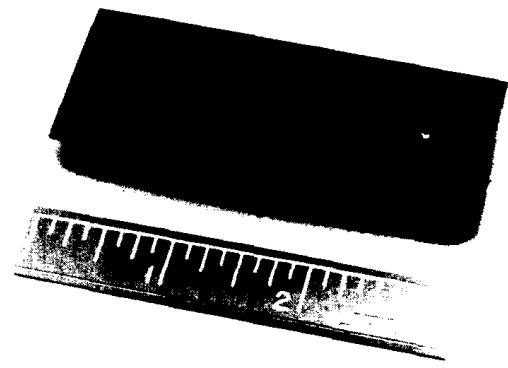

(b)

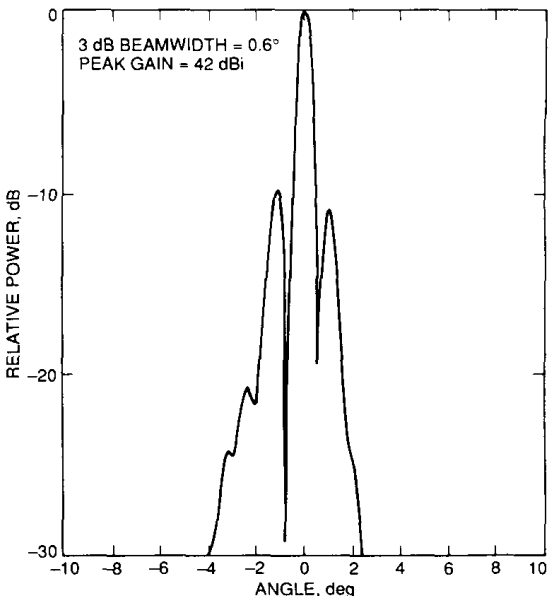

Fig. 9. Ku-band antenna breadboard test model. (a) Reflector/array test model; (b) 4-element series feed microstrip array antenna; (c) the measured cross-track fan-beam pattern at $10.5^{\circ}$ look angle of the Ku-band antenna breadboard test model; (d) the measured along-track fan-beam pattern at $10.5^{\circ}$ look angle of the Ku-band antenna breadboard test model. (Courtesy of J. Huang.)

ceiver gain and bandwidth; initiates periodic system testing and calibration; and digitizes, buffers, formats and routes both science (radar data) and engineering (e. g., spacecraft ephemeris and attitude) telemetry to the spacecraft's data stream. In addition, it also monitors the health of the instrument and reports any system anomalies.

The power subsystem is responsible for the conversion of the spacecraft's $30-\mathrm{V}$ dc power to the regulated voltages required by the radar, and for providing proper fusing, recovery relays, and electromagnetic/radio-frequency filtering.

The entire radar electronic assembly will be installed in a spacecraft's electronics bay. Current estimates on the mass and power consumption of the complete radar system are $21.7 \mathrm{~kg}( \pm 30 \%)$ and $75.1 \mathrm{~W}( \pm 20 \%)$, respectively.

\section{IMAGING MODE DESCRIPTION}

From signal detection considerations, the maximum alti- tude for imaging is $\sim 4000 \mathrm{~km}$. This translates into $32 \mathrm{~min}$ (16 min before, until $16 \mathrm{~min}$ after the closest approach) of imaging time during a nominal Titan flyby pass. The limited number of encounters, coupled with the relatively short operation time, has necessitated the development of a wideswath imaging capability for the radar in order to obtain good overall surface coverage. As discussed in the previous sections, our approach is to generate six antenna beam patterns using the $3.66-\mathrm{m}$ high-gain telecommunications antenna with two sets of offset feed arrays. These feed arrays are designed to permit sequential surface illumination by six cross-track fan beams, and thus to generate three adjacent swaths on the left and three adjacent swaths on the right side of the spacecraft ground track. By a cyclic switching of the antenna beams, two continuous surface image strips, one on each side of the subsatellite track and each consisting of three adjacent substrips, can be achieved. The half-power beamwidths of each fan beam are $1.2^{\circ}$ in elevation and $0.45^{\circ}$ in azimuth, respectively. The composite 


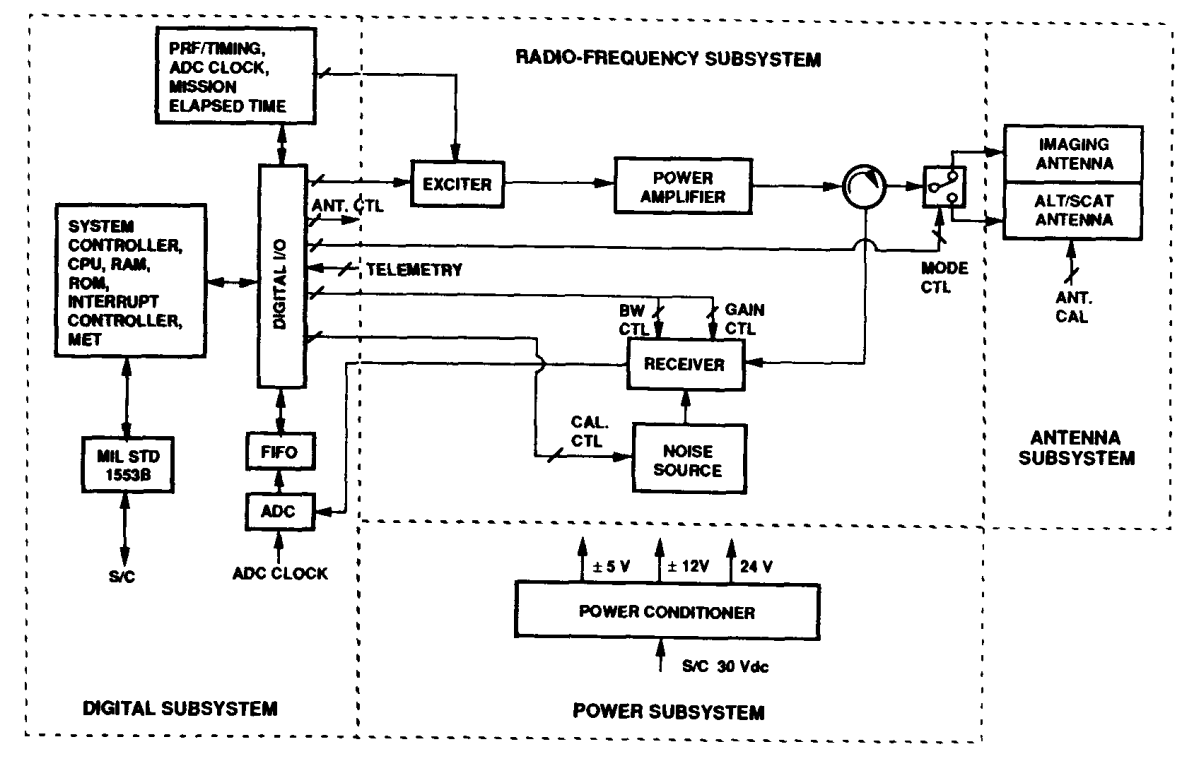

Fig. 10. Block diagram of the Cassini Titan Radar Mapper instrument.

Table 2 Comparison Between the Performance Requirements, the Calculated, and the Measured Performance for the Ku-band Side-Looking Antenna Beams

\begin{tabular}{l|c|c|c}
\hline Parameters & Requirements & $\begin{array}{c}\text { Calculated } \\
\text { Results }\end{array}$ & $\begin{array}{c}\text { Measured } \\
\text { Results }\end{array}$ \\
\hline $\begin{array}{l}\text { Peak gain } \\
\text { (dB) }\end{array}$ & 44.0 & 43.0 & 42.0 \\
$\begin{array}{l}\text { Azimuth } \\
\text { beamwidth } \\
\text { (deg) }\end{array}$ & 0.45 & 0.6 & 0.6 \\
$\begin{array}{l}\text { Range } \\
\text { beamwidth } \\
\text { (deg) }\end{array}$ & 1.2 & & \\
$\begin{array}{l}\text { Look angle } \\
\text { (deg) }\end{array}$ & $\pm 10.5, \pm 11.7$, & $\pm 10.5, \pm 11.7$, & $\pm 10.5, \pm 11.7$, \\
& \pm 12.9 & \pm 12.9 & \pm 12.9 \\
$\begin{array}{l}\text { Peak } \\
\text { side-lobe } \\
\text { (dB) }\end{array}$ & -15 & -16 & -10 \\
$\begin{array}{l}\text { Peak } \\
\text { cross-pol } \\
\text { (dB) }\end{array}$ & -15 & & \\
\hline
\end{tabular}

radar images created by summing the three adjacent image sub-strips will have a cross-track swath varying from 67 $\mathrm{km}$ at closest approach (1000 km altitude) to $310 \mathrm{~km}$ at the maximum range of $4000 \mathrm{~km}$. Given 32 min of imaging time, approximately $1.5 \%$ of Titan's surface can be mapped during each flyby.

The Cassini Titan Radar Mapper, when operating as an imager, would use aperture synthesis in order to obtain finer resolution in azimuth than that possible from the physical beamwidth of the real aperture antenna [27], [28]. In this method, radar echoes collected from a set of uniformly spaced points along the ground track are processed coherently in order to synthesize a larger aperture with a narrower "equivalent" beamwidth which allows finer azimuth resolution. This azimuth resolution will be complemented by similar cross-range resolution through the use of an appropriate system bandwidth. To accommodate the anticipated large variations in range, geometry, and radar reflectivity, the radar has the capability for imaging at three spatial resolution scales: high resolution imaging (HRI, approximately $500 \mathrm{~m}$ by $500 \mathrm{~m}$ ), medium resolution imaging (MRI, approximately $750 \mathrm{~m}$ by $1120 \mathrm{~m}$ ), and low resolution imaging (LRI, approximately $1300 \mathrm{~m}$ by 1800 $\mathrm{m})$. Table 3 summarizes the radar system and performance parameters for the imaging mode.

For the purposes of designing the radar instrument, the geometry we have considered is a straight-line path over a spherical Titan with radius of $2575 \mathrm{~km}$. The velocity of the spacecraft is assumed to be constant at $5.75 \mathrm{~km} / \mathrm{s}$, and the nominal minimum spacecraft altitude is $1000 \mathrm{~km}$. The nominal radar operation scenario will be for the Cassini spacecraft to slowly rotate during the encounter, in such a manner that the antenna would continue to point at the center of Titan. The uncertainties in the spacecraft's ephemeris and attitude control during each Titan encounter are relatively large. Since the required radar resolution is relatively low, the images can be acquired in an unfocused 
SAR mode which is robust with regard to ephemeris errors. Precise geocoding will require the high accuracy ephemeris which can be obtained from the post-encounter analysis. Such limitations have necessitated the use of burst mode timing for radar operation. In this timing approach, a series of pulses is transmitted for a burst period slightly less than one round-trip time to the surface and back. The radar then switches to receive and records the echoes from the burst of pulses. Consequently, uncertainty in timing due to errors in the position and pointing can be accommodated by adjusting the burst period and recording window rather than adjusting the pulse-to-pulse timing, as in the case of the conventional pulse interleave approach. When the spacecraft's ephemeris and attitude uncertainties are large, the burst mode approach is more effective at utilizing the limited allocations of data rate and data storage as well as at lowering the probability of data loss. With the assumed geometry, the burst period varies between 6.5 and $27.7 \mathrm{~ms}$ over a flyby pass, and it will be updated every $30 \mathrm{~s}$.

The radar instrument will multiplex the selected operational modes (imaging, altimetry, etc.) in repeated cycles along the spacecraft's trajectory. The duration of each cycle is determined by the smallest radar azimuth footprint size at nadir generated by the altimeter mode. By choosing this smallest footprint size, contiguous along-track coverages for all radar modes are ensured. With the assumed flyby geometry, the cycle duration varies from 1.6 to $22.2 \mathrm{~s}$ during the encounter. The division of this cycle time to the various radar modes, under the constraint of the maximum data rate and power allocations imposed by the spacecraft, must be carefully planned in order to maintain good balance on data quality obtained by different modes. The bandwidths, burst frequencies, data windows, sampling rates, and quantization resolutions must also be designed such that they will be consistent with the data rate allocations. In the current design, the maximum data rate allocated to the imaging mode, as shown in Table 3, varies between $80 \mathrm{~kb} / \mathrm{s}$ for low-resolution imaging and $250 \mathrm{~kb} / \mathrm{s}$ for high-resolution imaging.

For the geometry considered, the number of imaging bursts varies between 12 and 48 per cycle during the encounter. Depending on the burst durations, each burst contains between 27 and 62 pulses. A 2-b block adaptive quantization scheme similar to that used by the Magellan radar system is planned for quantizing the imaging data. A 2-b block adaptive quantizer introduces quantization noise at level $8.5 \mathrm{~dB}$ below the input signal when the receiver gain is set at the optimum value [29]. Magellan simulations with actual SAR data have shown that thermal SNR values better than the $8.5 \mathrm{~dB}$ do not improve the visual-image interpretation, while lower values degraded the images [29]. For the imaging mode of the Titan Radar Mapper, the measurement's thermal SNR is expected to be in the same range as those for the Magellan radar. This leads us to adopt a quantization strategy similar to Magellan's [29]. In the present design, the radar will use signal statistics to set the receiver gain in order to minimize the mean-squared error of the signal samples.
Table 3 Radar Parameters for the Imaging Mode of the Titan Radar Mapper

\begin{tabular}{|c|c|c|c|}
\hline $\begin{array}{l}\text { Time } \\
\text { (minutes) }\end{array}$ & $(-6,6)$ & $\begin{array}{l}(-12,-6) \text { and } \\
(6,12)\end{array}$ & $\begin{array}{l}(-16,-12) \\
\text { and }(6,12)\end{array}$ \\
\hline Altitude (km) & 1000 to 1556 & 1556 to 2895 & 2895 to 4002 \\
\hline $\begin{array}{l}\text { Transmit } \\
\text { power (W) }\end{array}$ & 65 & 65 & 65 \\
\hline $\begin{array}{l}\text { Imaging } \\
\text { mode }\end{array}$ & HRI & MRI & LRI \\
\hline $\begin{array}{l}\text { Chirp } \\
\text { bandwidth } \\
\text { (MHz) }\end{array}$ & 1.00 & 0.50 & 0.25 \\
\hline $\begin{array}{l}\text { Antenna gain } \\
\text { (dB) }\end{array}$ & 44.4 & 44.4 & 44.4 \\
\hline $\begin{array}{l}\text { Noise } \\
\text { temperature } \\
\text { (K) }\end{array}$ & 800 & 800 & 800 \\
\hline $\begin{array}{l}\text { Transmit path } \\
\text { loss (dB) }\end{array}$ & 2.0 & 2.0 & 2.0 \\
\hline $\begin{array}{l}\text { Receive path } \\
\text { loss (dB) }\end{array}$ & 2.5 & 2.5 & 2.5 \\
\hline $\begin{array}{l}\text { Cycle } \\
\text { duration (s) }\end{array}$ & 1.6 to 3.4 & 3.4 to 11.0 & 11.0 to 22.2 \\
\hline $\begin{array}{l}\text { Number of } \\
\text { bursts/cycles }\end{array}$ & 2 & 3 to 6 & 6 to 8 \\
\hline $\begin{array}{l}\text { Burst } \\
\text { duration (ms) }\end{array}$ & 6.5 to 11.1 & 10.3 to 20.4 & 19.6 to 28.6 \\
\hline PRF (Hz) & 3698 to 4158 & 2717 to 3698 & 2260 to 2717 \\
\hline $\begin{array}{l}\text { Max. data } \\
\text { rate }(k b / s)\end{array}$ & 250 & 150 & 80 \\
\hline $\begin{array}{l}\text { Ground range } \\
\text { resolution } \\
(\mathrm{km})\end{array}$ & 0.4 to 0.5 & 0.6 to 1.0 & 1.0 to 1.6 \\
\hline $\begin{array}{l}\text { Azimuth } \\
\text { resolution } \\
(\mathrm{km})\end{array}$ & 0.6 to 0.7 & 1.0 to 1.8 & 1.8 to 2.1 \\
\hline $\begin{array}{l}\text { Incidence } \\
\text { angle (deg) }\end{array}$ & 14.0 to 18.6 & 16.4 to 28.9 & 22.2 to 35.4 \\
\hline $\begin{array}{l}\text { Swath } \\
\text { width/side } \\
(\mathrm{km})\end{array}$ & 68 to 107 & 107 to 211 & 211 to 311 \\
\hline $\begin{array}{l}\text { Noise equiv, } \\
\sigma_{o}(\mathrm{~dB})\end{array}$ & $\begin{array}{l}-25.3 \text { to } \\
-18.9\end{array}$ & $\begin{array}{l}-20.9 \text { to } \\
-11.4\end{array}$ & -13.6 to -8.5 \\
\hline $\begin{array}{l}\text { Number of } \\
\text { looks }\end{array}$ & 4 & 9 to 20 & 20 to 32 \\
\hline $\begin{array}{l}\kappa_{p} \\
\left(\sigma_{o}=-10\right. \\
\mathrm{dB})\end{array}$ & 0.50 to 0.52 & 0.29 to 0.34 & 0.23 to 0.27 \\
\hline
\end{tabular}

The ground range resolution of the radar images is achieved by pulse compression of the received echoes. With this technique, the ground range resolution is a function of the system bandwidth and the angle of incidence. The 


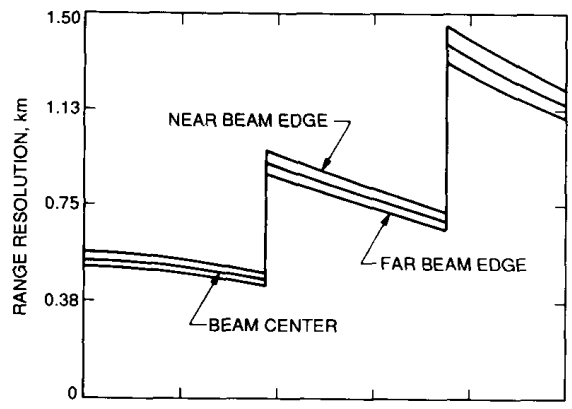

(a)

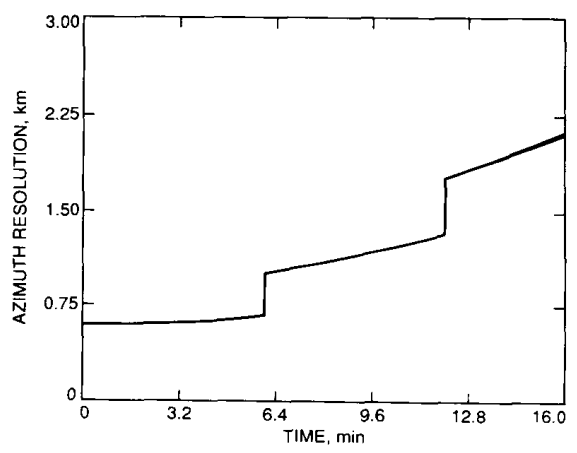

(b)

Fig. 11. (a) Ground range resolution in kilometers across the beam, with the center look angle of $11.7^{\circ}$, as a function of time since the closest approach; (b) Azimuth resolution, in kilometers, for the beam with a center look angle of $11.7^{\circ}$, as a function of time since closest approach. The three regions correspond to the three different signal bandwidths. The beam center and the nearand far-edges in the figure correspond to the center and the two edges of the radar-illuminated surface footprint in the cross-track direction.

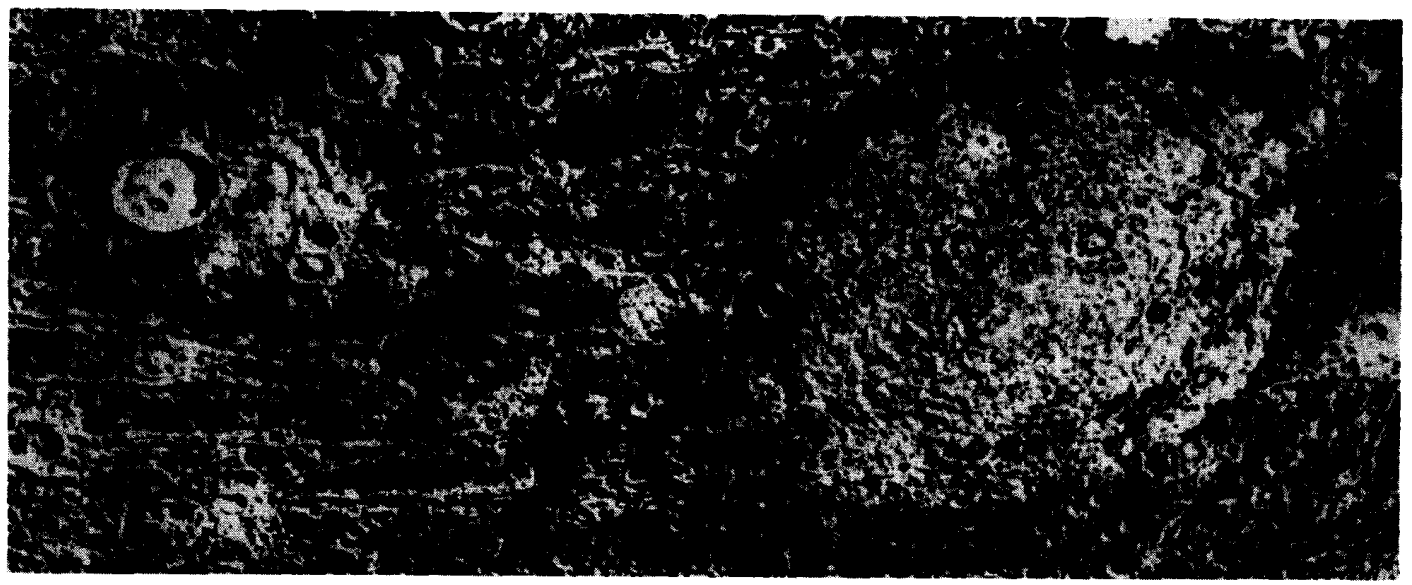

Fig. 12. The Voyager 2 image of Ganymede from a distance of $85000 \mathrm{~km}$. The resolution is $1.2 \mathrm{~km}$, the swath width is $250 \mathrm{~km}$.

ground range resolution decreases with increasing incidence angle. As an example, the incidence angle associated with the $11.7^{\circ}$ side-looking imaging beam varies between $16.3^{\circ}$ at closest approach to $31.2^{\circ}$ at a range of $4000 \mathrm{~km}$, and this results in a factor of two improvement in range resolution if a constant bandwidth is being used. On the other hand, the echo signal-to-noise ratio decreases with range and this consideration must be traded against the resolution considerations. In the current design, the selected chirp bandwidths are 1.0, 0.5 and $0.25 \mathrm{MHz}$ for HRI,
MRI, and LRI operations, respectively. In Fig. 11(a), the corresponding ground range resolution is shown across the middle beam.

Each burst of radar raw data is processed to full resolution and then degraded in order to obtain independent samples of the scene (looks). This is done to reduce speckle noise in the image and to have pixels which have similar resolutions in range and azimuth. The number of looks from each burst varies between 2 and 4 depending on the range resolution and incidence angle. Time-domain correlation filtering of 


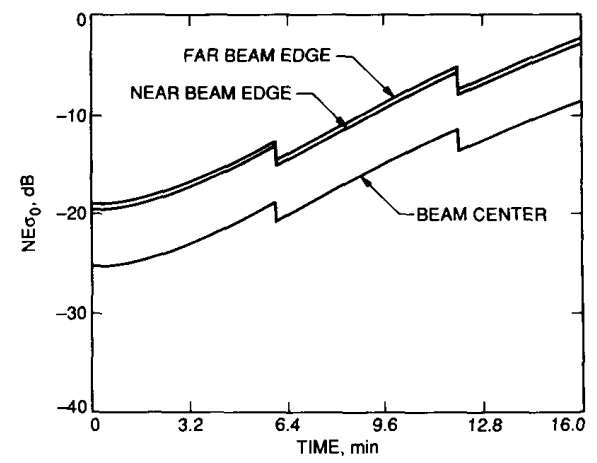

Fig. 13. Noise equivalent $N E \sigma_{o}$, in decibels, for the $11.7^{\circ}$ look angle beam as a function of time since closest approach.

the received signal samples will be used to obtain the synthesized aperture resolution. In Fig. 11(b), the azimuth resolution for the $11.7^{\circ}$ look angle case is shown as a function of time since closest approach. It can been seen that the azimuth resolutions for image pixels across the beam is rather uniform.

An example which shows the expected resolution and swath width of the images which the Cassini Titan Radar Mapper will obtain is shown in Fig. 12. This Voyager 2 photo of the icy surface of Jupiter's Ganymede, taken at a distance of $85000 \mathrm{~km}$ and with the resolution of 1.2 $\mathrm{km}$, shows a narrow tract of Ganymede's grooved terrain. Recent Earth-based radar observations have demonstrated the radar cross section of Titan to be consistent with the cross sections of the icy Galilean satellites, including Ganymede [3].

Because of the present uncertainty regarding the backscattering characteristics of Titan's surface, it is more meaningful to characterize the radar detection sensitivity in terms of the so-called noise equivalent $\sigma_{o}\left(N E \sigma_{o}\right)$. This quantity is defined as the value of the surface backscattering coefficient which gives rise to a unity SNR. Using the parameters listed in Table 3, the resulting $N E \sigma_{o}$ across the $11.7^{\circ}$ look angle beam is shown in Fig. 13. There is a 6-dB reduction in $N E \sigma_{o}$ at the near and far ranges since the two-way antenna gain is reduced by this amount at the beam edges.

\section{ALTIMETRY AND SCATTEROMETRY}

The relative surface elevation of Titan will be measured by the Titan Radar Mapper when it operates as a narrowbeam radar altimeter. From signal-to-noise and data rate considerations, the altimeter mode is planned to operate from $12 \mathrm{~min}$ before the closest Titan approach of each Titan flyby until $12 \mathrm{~min}$ after the closest encounter. During this 24-min period the altimeter will time-share with other selected operational modes such that topographic measurements along the subsatellite track will be collected.

Similar to the imaging mode, the altimeter mode will operate at the center frequency of $13.8 \mathrm{GHz}$ (Ku-band). When this mode is executed, bursts of frequency-modulated
Table 4 Radar Parameters for the Altimeter and Scatterometer Modes of the Titan Radar Mapper

\begin{tabular}{l|cc}
\hline & Altimeter & Scatterometer \\
\hline \hline Frequency (GHz) & 13.8 & 13.8 \\
Transmit power (W) & 65 & 65 \\
$\begin{array}{l}\text { Half-power antenna } \\
\text { beamwidth (deg) }\end{array}$ & 0.4 & 0.4 \\
$\begin{array}{l}\text { Antenna gain at } \\
\text { boresight (dB) }\end{array}$ & 50.4 & 50.4 \\
$\begin{array}{l}\text { Peak antenna } \\
\text { sidelobe (dB) }\end{array}$ & -15 & -15 \\
$\begin{array}{l}\text { Transmit pulse } \\
\text { duration ( } \mu \text { s) }\end{array}$ & 150 & 150 \\
$\begin{array}{l}\text { Chirp bandwidth } \\
\text { (MHz) }\end{array}$ & 5.0 & 0.05 \\
PRF (kHz) & 5.0 & 1.0 to 3.0 \\
$\begin{array}{l}\text { Transmit path loss } \\
\text { (dB) }\end{array}$ & 2.0 & 2.0 \\
$\begin{array}{l}\text { Receive path loss } \\
\text { dB) }\end{array}$ & 2.5 & 2.5 \\
$\begin{array}{l}\text { System noise } \\
\text { temperature (K) }\end{array}$ & 800 & 800 \\
\hline
\end{tabular}

pulse signals of $150 \mu \mathrm{s}$ time duration and at $5 \mathrm{MHz}$ bandwidth will be transmitted. Depending on the radar range, mode multiplexing strategy used, and the data rate allocation profile, the number of pulses transmitted in each burst will vary throughout a single flyby pass. In order to obtain the best possible signal power and spatial resolution, the entire antenna reflector will be illuminated by the $\mathrm{Ku}$ band center feed. Computer-controlled time gating will be performed such that the entire range history of the echo intensity (waveform) as well as the round-trip delay time will be recorded for data analysis. The range resolution of the measurements will be recovered after pulse compression during ground processing. Measurement accuracy will be further improved by incoherent averaging of 50 to 100 measurements to reduce the speckle noise. The nominal radar parameters for the altimeter mode are shown in Table 4.

The nadir radar altimetry concept is very simple and straightforward. A radar altimeter transmits short electromagnetic pulses and measure the round-trip propagation time of these pulses as they are reflected from a surface and detected by the radar receiver. The absolute surface elevation $(h)$ and relative surface elevation $(\Delta h)$ can be reconstructed according to:

$$
\begin{gathered}
h=H-R=H-\frac{\nu_{a} t}{2} \\
\Delta h=h_{2}-h_{1}=\left(H_{2}-H_{1}\right)-\frac{\nu_{a}\left(t_{2}-t_{1}\right)}{2}
\end{gathered}
$$


where $h$ is the surface elevation relative to a reference plane (geoid), $H$ is the spacecraft altitude relative to the same geoid, $R$ is the measured one-way range, $t$ is the roundtrip pulse propagation time, and $\nu_{a}$ is the average pulse propagation speed through Titan's atmosphere. In principle, with the knowledge of $H$ and by accurately measure the pulse propagation time, the absolute surface elevation can be reconstructed according to (4). However, due to the limitations on Cassini spacecraft's navigation capability, the extraction of absolute surface elevation will not be possible. On the other hand, the relative surface elevation may still be measured according to (5) because the spacecraft's height trajectory at each flyby is expected to be a smooth function of time (with short-term perturbation very close to zero) and can be reconstructed accurately during ground processing.

The overall measurement accuracy depends on the measurement resolution, ranging and surface geometries, pointing, and processing algorithms. A previous study has indicated that centroid-type algorithms perform reasonably well for natural topographic features [30]. By identifying the various possible error sources and with reasonable estimates of their contributions, a worst-case error budget is derived and tabulated in Table 5. For the described system approach, our preliminary assessment is that an overall relative elevation measurement accuracy of $80 \mathrm{~m}$ or better can be achieved.

The lack of information on the backscattering strength of Titan's surface and its spatial variations has been a major concern during the course of the radar design. In order to compensate for the possibility that Titan's surface is unexpectedly radar-dark, and to ensure credible measurements of the surface backscatter variations, we have incorporated a special scatterometer mode into the overall radar design. The functional concept of the scatterometer mode is similar to that of the altimeter with a major difference. Instead of a 5-MHz bandwidth, the scatterometer will use a $50-\mathrm{KHz}$ bandwidth. The system parameters for the scatterometer mode are also given in Table 4 . The use of a smaller bandwidth will not change the $N E \sigma_{o}$ when the surface is relatively smooth. It will, however, lower the $N E \sigma_{o}$ significantly if a surface has large topographic variations. With the chosen design, a $20-\mathrm{dB}$ improvement in $N E \sigma_{o}$ is expected if the surface slope is larger than the ratio of the vertical to horizontal resolution. As a result of this improvement, the acquisition of scatterometric measurements can be extended to a longer time period. In our current plan, it will operate from $30 \mathrm{~min}$ before until $30 \mathrm{~min}$ after the closest Titan encounter with the farthest range distance equal to $8375 \mathrm{~km}$. In Fig. 14, the $N E \sigma_{o}$ achievable by the scatterometer mode is plotted versus the flyby altitudes for different values of surface slopes.

The backscatter measurement accuracy, $K_{p}$, is defined as the ratio of the standard deviation of the signal power measurements $\left(\operatorname{std}\left\{P_{s}\right\}\right)$ to the mean signal power $\left(\left\langle P_{s}\right\rangle\right)$ [31], [32]

$$
K_{p}=\frac{\operatorname{std}\left\{P_{s}\right\}}{\left\langle P_{s}\right\rangle}
$$

Table 5 The Error Budget for the Relative Elevation Measurements of the Altimeter Mode of the Titan Radar Mapper

\begin{tabular}{l|c}
\hline \multicolumn{1}{|c|}{ Error Source } & Worst-case Errors (m) \\
\hline Vertical resolution & 51 \\
Pointing & 50 \\
Ephmeris & 10 \\
Processing & 35 \\
Atmosphere & 5 \\
\hline \multicolumn{1}{c}{ Total (RSS) } & 80 \\
\hline
\end{tabular}

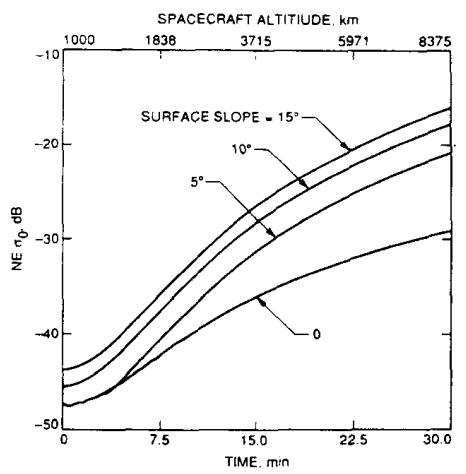

Fig. 14. Thermal-noise-equivalent $\sigma_{o}$ of scatterometry measurements at average surface slopes of $0,10^{\circ}, 20^{\circ}$, and $30^{\circ}$.

In our approach, the mean power of the scatterometric measurements, $\left\langle P_{s+n}\right\rangle$, and the mean power of the noise-only measurements, $\left\langle P_{n}\right\rangle$, will be estimated through coherent averaging of $\mathrm{N}$ independent measurements. In turn, $\left\langle P_{s}\right\rangle$ is estimated by subtracting $\left\langle P_{n}\right\rangle$ from $\left\langle P_{s+n}\right\rangle$. Since the variance of the noise-only power estimate equals the variance of the signal plus noise estimate, $K_{p}$ is given by [15]

$$
K_{p}=\frac{1}{\sqrt{N}}\left[1+\frac{2}{S N R}+\frac{2}{S N R^{2}}\right]^{1 / 2} .
$$

In (4), it is assumed that the signal fluctuations are only due to thermal noise and speckle and not caused by fluctuations in the system parameters such as the transmitted power or noise temperature during the times that $P_{s+n}$ and $P_{n}$ measurements are obtained. It can be seen from (4) that both the $S N R$ and the number of independent measurements affect the backscatter measurement accuracy and that even if the $S N R$ is low, acceptable accuracy can be obtained by increasing the number of measurements. With the current scatterometer design, surface backscatter measurement accuracies better than $30 \%$ are anticipated.

\section{SUMMARY}

The Cassini Titan Radar Mapper has been designed to have a wide range of capabilities in order to encompass a variety of possible surface properties. This is required 
because of the almost complete lack of knowledge of Titan's surface conditions. The scatterometer mode will provide important information over areas of extremely low backscatter such as the putative smooth ethane/methane ocean. The altimeter mode will provide information on various surface topographic features. The high-resolution imaging mode will allow detailed observation of surfaces with relatively strong backscatter. The design of the instrument will allow multiplexing of different modes at each flyby and it will accommodate a wide range of instrumentto-surface distances and geometries.

Because of the limited number of flybys, there was a necessity of having simultaneous multimode capability. This has been achieved by using a multifeed antenna system which allowed coverage of multiple swaths on both sides of the spacecraft as well as the nadir observation.

\section{ACKNOWLEDGMENT}

The authors would like to thank J. Huang of the Jet Propulsion Laboratory for providing data as well as constructive comments on Section IV.

\section{REFERENCES}

[1] L. Trafton, "Atmospheres of outer planets and satellites," Revs. Geophys. Space Phys., vol. 19, pp. 43-89, 1981.

[2] T. Owen, "The composition and origin of Titan's atmosphere," Planet. Space Sci, vol. 30, pp. 833-838, 1982.

[3] D. O. Muhleman, A. W. Grossman, B. J. Butler, and M. A. Slade, "Radar reflectivity of Titan," Science, vol. 248, pp. $975-980,1990$

[4] D. F. Strobel, "Chemistry and evolution of Titan's atmosphere," Planet. Space Sci., vol. 30, pp. 839-848, 1982.

[5] D. M. Hunten, M. G. Tomasko, F. M. Flasar. R. E Samuelson, D. F. Strobel, and D. J. Stevenson, "Titan," in Saturn, T. Gehrels and M. S. Matthews, Eds. Tucson, AZ: University of Arizona Press, 1984, pp. 671-759.

[6] G. F. Lindal, G. E. Wood, H. B. Hotz, D. N. Sweetnam, V. R. Eshleman, and G. L. Tyler, "The atmosphere of Titan: An analysis of the Voyager 1 radio occultation measurements," Icarus, vol. 53, 348-363, 1983.

[7] Y. L. Yung, M. Allen, and J. P. Pinto, "Photochemistry of the atmosphere of Titan: Comparison betwen model and observations," Astrophys. J., vol. 55, pp. 465-506, 1984.

[8] C. Sagan, and S. F. Dermott, "The tide in the sea of Titan," Nature, vol. 300, pp. 731-733, 1982.

[9] J. L. Lunine, D. J. Stevenson, and Y. L. Yung, "Ethane ocean on Titan," Science, vol. 222, pp. 1229-1230, 1983.

[10] W. K. Hartmann, Moons and Planets. Belmont, CA: Wadsworth, 1983, p. 44.

[11] J. L. Lunine, and D. J. Stevenson, "Evolution of Titan's coupled ocean-atmosphere system and interaction of ocean with bedrock," in Ices in the Solar System, J. Klinger, D. Banest, A. Dollfuss, and R. Smoluchowski, Eds. Dordrecht: D. Reidel, 1985, pp. 741-757.

[12] R. Rebiai, A. J. Rest, and R. G. Scurlock, "The unexpected high solubility of water in cryogenic liquids," Nature, vol. 305, pp. $412-413,1983$.

[13] O. B. Toon, C. P. McKay, R. Courtin, and T. P. Ackerman, "Methane rain on Titan," Icarus, vol. 75, pp. 255-284, 1988.

[14] J. L. Lunine, "Titan's surface and implications for Cassini," in The atmospheres of Saturn and Titan, European Space Agency SP-241, pp. 83-88, 1985.

[15] F. T. Ulaby, R. K. Moore, and A. K. Fung, Microwave Remote Sensing, vol. 2. Reading, MA: Addison-Wesley, 1982, pp. $853-860$

[16] R. H. Stewart, Methods of Satellite Oceanography. Berkeley, CA: University of California Press, 1985, pp. 208-224.

[17] B. Kinsman, Wind Waves. Englewood Cliffs, NJ: Prentice Hall, 1965. (Reprint, NY: Dover Publications, 1984, pp. 74-178. 297-300.)
[18] J. Lighthill, Waves in Fluids. Cambridge: Cambridge University Press, 1978 , pp. 223-225

[19] V. A. M. Soares, B. S. Almeida, I. A. McLure, and R. A. Higgins, "Surface tension of pure and mixed simple substances at low temperatures," Fluid Phase Equilibria, vol. 32, pp. 9-16, 1986

[20] V. A. M. Soares, I. A. McClure, B. S. Almeida, R. A. Higgins, and J. C. G. Calado, "Cell for orthobaric surface tension measurements at low temperatures," Cryogenics, vol. 27, pp. 263-265, 1987.

[21] A. J. Leadbetter, D. J. Taylor, and B. Vincent, "The densities and surface tensions of liquid ethane and nitrous oxide," Canad. J. Chem., vol. 42, pp. 2930-2932, 1964.

[22] G. H. Pettengill, "Physical properties of the planets and satellites from radar observations," Ann. Rev. Astron. Astrophys., vol. 16, pp. 265-292, 1978.

[23] S. J. Ostro, "Planetary radar astronomy," in Encyclopedia of Physical Science and Technology. NY: Academic Press, vol. 10 , pp. 611-634.

[24] S. J. Ostro, and E. M. Shoemaker, "The extraordinary radar echoes from Europa, Ganymede, and Callisto: A geological perspective," Icarus, vol. 85, pp. 335-345.

[25] M. Fulchignoni, "The discovery of the Saturn's system: Cassini's life and activity," in Atmospheres of Saturn and Titan, ESA SP-241, 1985, pp. 289-294.

[26] J. Huang and Y. Rahmat-Samii, "Fan beam generated by a linear-array fed parabolic reflector," IEEE Trans. Antennas Propagat., vol. AP-38, pp. 1046-1053, 1989.

[27] K. Tomiyasu, "Tutorial review of synthetic-aperture radar (SAR) with applications to imaging of the ocean surface," Proc. IEEE, vol. 66, pp. 563-583, 1978

[28] C. Elachi, Spaceborne Radar Remote Sensing: Applications and Techniques. NY: IEEE Press, 1988.

[29] R. Kwok and W. T. K. Johnson, "Block adaptive quantization of Magellan SAR data," IEEE Trans. Geosci. Remote Sensing, vol. GE-27, pp. $375-383,1989$.

[30] C. Elachi, K. E. Im, F. Li, and E. Rodriguez, "Global digital topography mapping with a synthetic aperture scanning rada altimeter," Int. J. Remote Sensing, vol. 11, pp. 585-601, 1990.

[31] R. E. Fisher, "Standard deviation of scatterometer measurements from space," IEEE Trans. Geosci. Electronics, vol. GE10 , pp. $106-113,1972$.

[32] C. Y. Chi, D. G. Long, and F. K. Li, "Radar backscatter measurement accuracies using digital processors in spaceborne scattermeters," IEEE Trans. Geosci. Remote Sensing, vol. GE24 , pp. $426-437,1986$.



Charles Elachi (Fellow, IEEE) received the B.Sc. in physics from the University of Grenoble, France, the Dipl. Ing. in engineering from the Polytechnic Institute, Grenoble, the M.Sc. degree in geology from the University of California, Los Angeles, and the M.Sc. and the Ph.D. degrees in electrical sciences from California Institute of Technology, Pasadena.

$\mathrm{He}$ is a Senior Research Scientist at the Jet Propulsion Laboratory, California Institute of Technology and the Assistant Laboratory $\mathrm{Di}$ rector for space science and instruments. He teaches physics of remote sensing at the California Institute of Technology. He has been a principal investigator on a number of research and development studies and fligh projects sponsored by the National Aeronautics and Space Administration. These include comparative imaging radar planetology, Earth imaging radar geology, imaging radar oceanography, polar ice mapping and dynamics, clectromagnetic sounding of a comet nucleus, study of venus cloud properties, multispectral Titan radar imager/sounder, Mars altimetry, and, more recently, the Shuttle Imaging Radar Series. He is the Team Leader of the Earth Observing System imaging radar, a coinvestigator on the Magellan imaging radar, and a Team Leader of the Cassini Titan Radar experiment. $\mathrm{He}$ is the author of over 200 publications in the fields of interpretation of active microwave remote sensing data, wave propagation and scattering, electromagnetic theory, lasers, and integrated optics, and he holds several patents in those fields.

Dr. Elachi is a member of the National Academy of Engineering. 


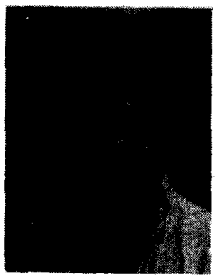

Eastwood Im received the B.S., the M.S., and the $\mathrm{Ph} . \mathrm{D}$. degrees in electrical engineering from the University of Illinois, Urbana, in 1981, 1982 and 1985 , respectively.

After joining the California Institute of Technology Jet Propulsion Laboratory in 1985, he has been working in various research areas on radar and optical remote sensing. He has developed radar signal processing algorithms for retrieving precipitation and surface topography, and has investigated the performance of twocolor laser ranging techniques for atmospheric correction and for measuring surface pressure and tectonic motions. He has also been involved in a number of system design studies on spaceborne precipitation radars, rada altimeters, and planetary imaging radars. Currently, he is active in the system engineering area of the Cassini Titan Radar Mapper developmen project. He is a science investigator for the Shuttle Imaging RadarC Precipitation Experiment and the Topical Rainfall Explorer Mission Experiment on the Space Station. He is the author of over 40 publications in refereed journals, conference proceedings, and technical reports.

Dr. Im is a member of the American Meteorological Society, Eta Kappa $\mathrm{Nu}$, and Tau Beta Pi. He was the recipient of the University of Illinois GT\&E Fellowship in 1984, and of Kemper and Exxon Fellowships, both in 1985 .

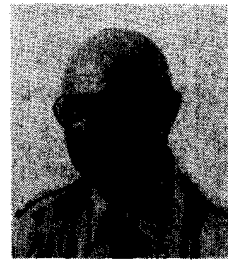

Ladislav E. Roth received the Dipl. Ing. degree in electrical engineering from the Czech Institute of Technology, Prague, Czechoslavakia and the M.Sc. degree in planetary and space physic from the University of California, Los Angeles. $\mathrm{He}$ is a member of the Technical Staff of Jet Propulsion Laboratory, California Institute of Technology, and is a Principal Investigator in the Planetary Geology and Geophysics Program of the National Aeronautics and Space Administration. His research interests include physica characteristics of surfaces of terrestrial planets, geologic processes on those surfaces, and questions related to the interpretation of the radar remote sensing data. In addition to Cassini Titan Radar, he has participated in a number of planetary radar experiments conducted by the Jet Propulsion Laboratory.

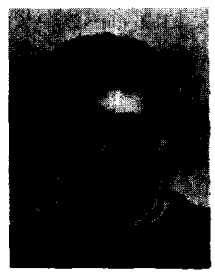

Charles L. Werner received the Ph.D. degree in systems engineering in 1987 from the University of Pennsylvania in Philadelphia. His research was in the area of high resolution radiometric imaging of distributed noise sources and microwave imaging implemented using polarization and frequency diversity.

At the Jet Propulsion Laboratory in Pasadena, CA he has worked on the digital reconstruction algorithms for synthetic aperture radar data obtained from both spaceborne and airborne radar.

There he pursued research in speckle reduction, scatterer classification, polarization signatures, and the absolute and relative calibration of SAR $\mathrm{He}$ has also studied implementations of the phase unwrapping algorithms for radar interferometry, the detection of moving objects in SAR data, and the absolute calibration of the JPL aircraft SAR and Shuttle Imaging Rada (SIR-C). Currently, he is developing the system design of the Cassini Titan radar mapper which is a multimode radar incorporating an altimeter and SAR modes. He is also a coinvertigator for the SIR-C mission involved with the interferometric and bistatic experiments. 